\title{
5 Combinations of the Dimensions of Aspectuality in the Situation Frame: the First Level of the Model Applied
}

\subsection{Introductory remarks}

In this chapter, I present an inventory of the combination patterns of the aspectual basic conceptualisations, as understood in the framework of the model presented in Chapter 4. These patterns are represented by schemas which illustrate the compositions of the three delimitation perspectives. I will refer to these as delimitation schemas. Each of the schemas is preceded by examples, some of which have already been partially presented in Chapter 4, where they were analysed from only one of the three perspectives of aspectuality. The inventory includes all possible and impossible combinations of the aspectual basic conceptualisations presented in the previous chapter. However, this illustrates only the first level of delimitation that has been considered so far, which means that further perspectivisations such as what would be called "progressive" in a traditional analysis of states of affairs - have no place here for the moment. In Chapter 6, I will present this second level of aspectuality, which is formally expressed by, in particular, verbal periphrases.

The inventory of the delimitation schemas is also a first application of the model developed here.

\subsection{Aspectual delimitation schemas}

\subsubsection{A comprehensive inventory of delimitation schemas}

The graphical representations of the aspectual delimitation schemas that illustrate the examples in this chapter (Tables (2)-(13)) show the now known tripartite division into the external, the adjacency-related and the internal perspectives of aspectual delimitation. The first three columns of the tables contain the diagrams already presented in Table (2) in the previous chapter (§4.4.2), which represent the complete inventory of the aspectual basic conceptualisations. The right-hand column contains a summarising illustration of the respective combinations of aspectual basic conceptualisations of the three perspectives of aspectuality where a combination is possible (these figures are introduced here); the impossibility of a combination is indicated by an X. 
There are only 11 possible combinations of the three realisations (or basic conceptualisations) of external aspectuality, the four realisations of adjacencyrelated aspectuality and the two realisations of internal aspectuality, that is, only 11 delimitation schemas and not 24 , which is due to the fact that a number of combinations are not possible. For example, states of affairs that are not externally delimited (EA/nd), and those that are represented as not internally subdivided (IA/ns) cannot be determined with regard to their adjacency, in other words they are indeterminable in terms of their adjacency relevance (NAA, see $\S 4.4 .4 .5)$. The former, for example, cannot be relevant for their adjacency, since they have no adjacency and therefore can only be combined with one realisation of adjacency-related aspectuality, namely that of non-relevance (AA/nr). Furthermore, states of affairs which are represented as externally punctually delimited (EA/pd) cannot be subdivided, are not internally subdivisble (NIA, see 4.4.5.3), since they have no duration; these can therefore only be combined with one realisation of internal aspectuality, i.e., the internally non-subdivided (IA/ns; for a more detailed explanation of these constraints see Chapter 4).

Table (1) first of all presents the entire inventory of the combinations of aspectual basic conceptualisations, which are explained in more detail in Tables (2)-(13): ${ }^{1}$

Tab. 1: Inventory of the delimitation schemas.

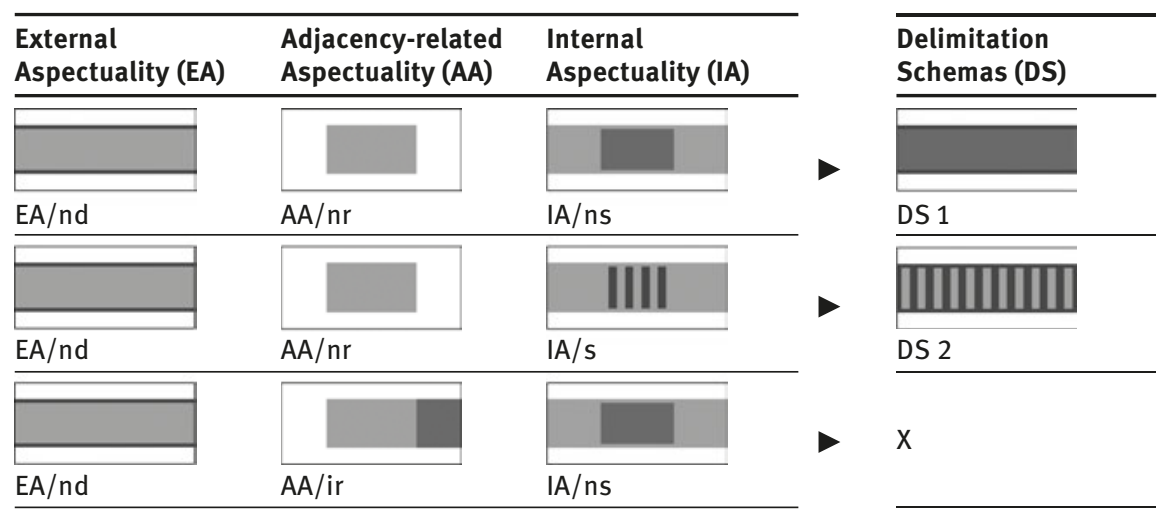

1 Apart from DS 12, combinations with NEA, NAA and NIA are not shown in this table because these three basic conceptualisations are contained respectively in EA/nd, AA/nr and IA/ns (see §4.4.3.4, §4.4.4.5 and §4.4.5.3). 
Tab. 1 (continued)

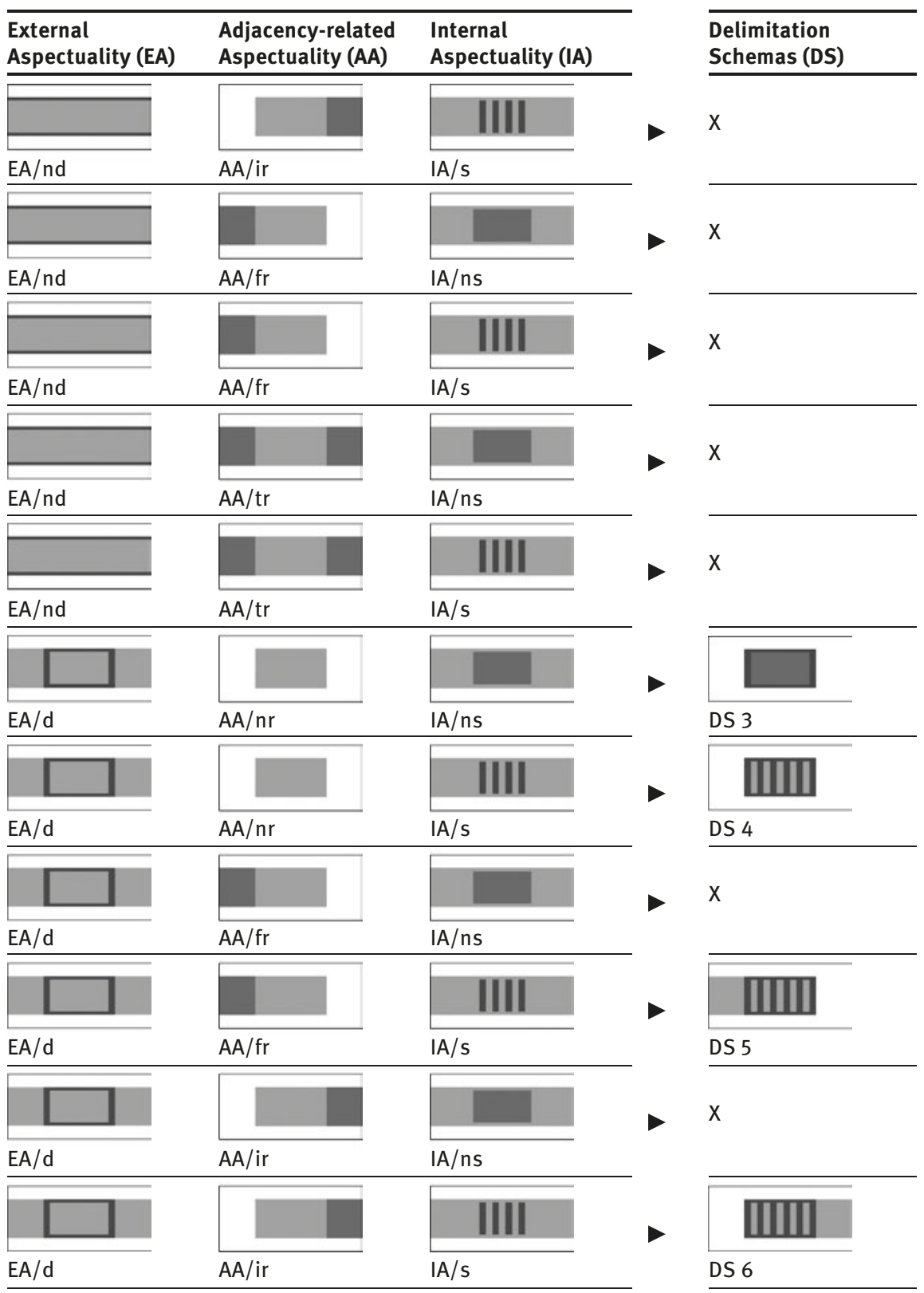


Tab. 1 (continued)

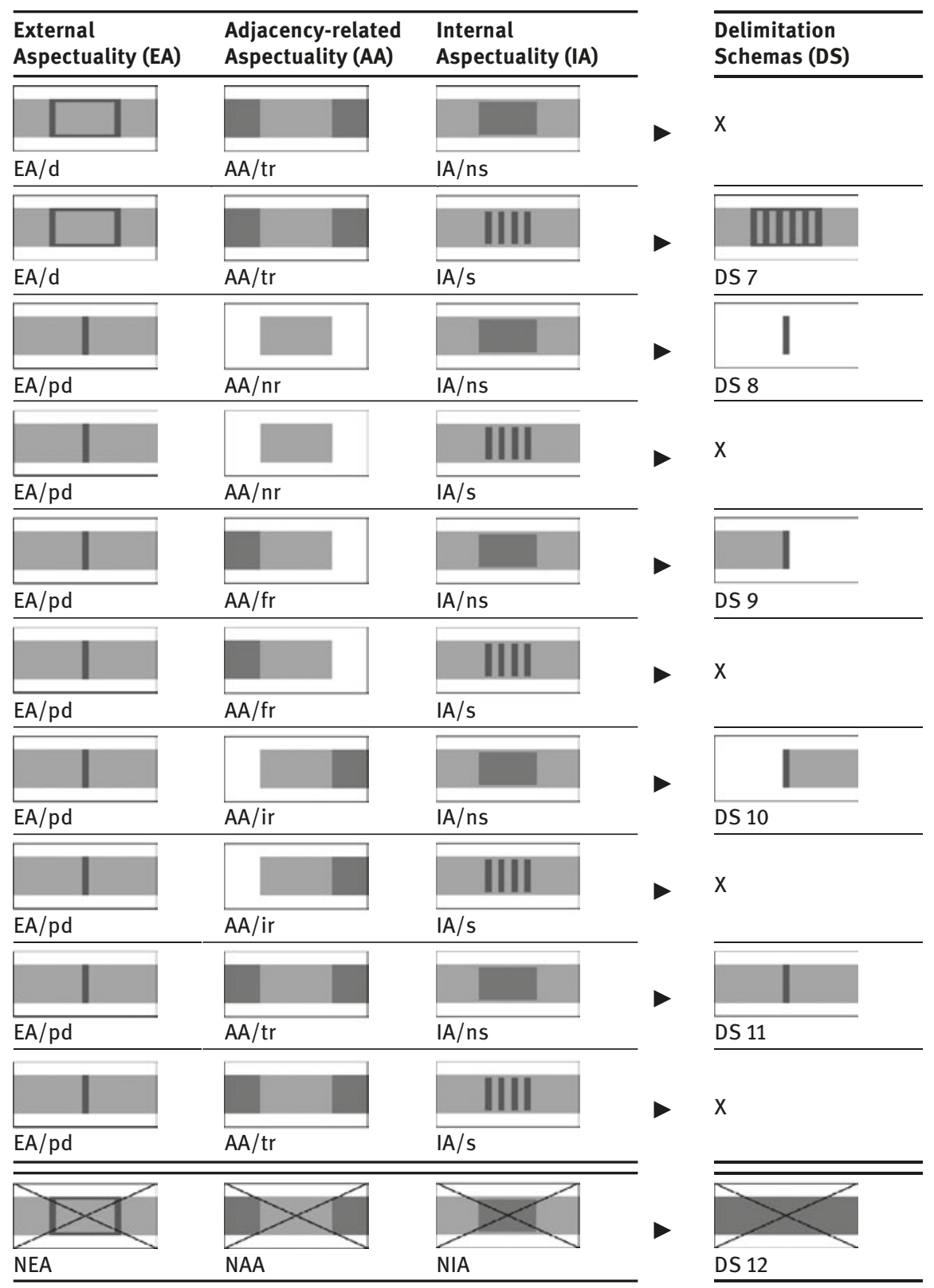


Delimitation schema number 12 is a special one (Table (13)). It is not the result of a combination of possible realisations of the three perspectives of aspectuality, but of non-aspectuality. It therefore represents atemporal states of affairs in which no aspectuality can be determined from either of the three perspectives. For this reason, it is listed separately in the complete inventory in Table (1).

As in the previous chapter (§§4.4.3ff.), examples from the four Romance languages examined, in which the content category of aspectuality is expressed by both lexical and grammatical means and which mostly have different tenses, are cited here and commented on in parallel to emphasise once again how different the formal means by which the Romance languages can express the same aspectual content information can be. ${ }^{2}$

\subsubsection{Presentation of the individual delimitation schemas}

\subsubsection{Delimitation Schema 1: $[(E A / n d)+(A A / n r)+(I A / n s)]$}

(1) It. Leo ha [Pres.] i capelli rossi. 'Leo has red hair.'

(2) Fr. Julie était [Imp.] grande pour son âge. 'Julie was tall for her age.'

(3) Sp. Marta tiene [Pres.] miedo de la lluvia. 'Marta is afraid of the rain.'

(4) Cat. La Rosina sap [Pres.] parlar moltes llengües. 'Rosina can speak many languages.'

States of affairs such as those illustrated in (1)-(4) exhibit a combination of aspectual basic conceptualisations of the following type:

a) externally non-delimited (EA/nd)

b) not relevant to adjacency $(\mathrm{AA} / \mathrm{nr})$

c) not internally subdivided (IA/ns)

2 Temporal markings of a deictic nature, that is, of the tense forms in the examples, are indicated in square brackets in the examples; special periphrastic constructions are noted in square brackets after the examples. 
In (1)-(4), a) neither a starting point $t_{x}$ nor an endpoint $t_{y}$ of the respective whole states of affairs is focussed, for neither the beginning nor the end of Leo having red hair in (1), Julie's height in (2), Marta's fear of rain in (3), nor Rosina's talent for languages in (4) are focussed: the respective states of affairs are not presented in their entirety and thus not in their completedness. Here, it is also b) logically impossible to determine the adjacency relevance, the relevance of Leo having red hair (as well as of Julie's height, Marta's fear of rain, or Rosina's talent for languages) for its adjacency, because, on the one hand, it is precisely the initial boundary $t_{x}$ and the final boundary $t_{y}$, which would constitute an adjacency, that are missing. On the other hand, c) (1)-(4) are monophasic states of affairs: no focussable moments $t_{x 1}, t_{x 2}, \ldots t_{x n}$ that could be (substantially) distinguished from each other can be found in the fact that Leo has red hair, that Julie is tall for her age, that Marta is afraid of the rain and that Rosina speaks many languages. I have already explained in $\$ 4.4 .1$ how the possibility of a change in time can only arise if there is a possibility of setting further subdivision points or boundaries in the temporal structuring of the state of affairs, since this variability lies precisely in the possibility of a change of state, the formation and ending of intervals and thus a temporal boundary setting. There can be no change in time where there are no discrete temporal subintervals, and vice versa: it is not possible to distinguish a moment $t_{x 1}$ of Leo having red hair (or of Julie's height, Marta's fear of rain, or Rosina's talent of languages) which is different from another $t_{\mathrm{x} 2}$ of his having red hair, in which he is more or less red-haired or in which he is red-haired in a different way. In this sense, we can define monophasic states of affairs as static states of affairs whose internal structure is homogeneous, not internally temporally further subdivided (that is, into further points $t_{x 1}, t_{x 2}, \ldots t_{x n}$ into which the interval $t_{x} \ldots t_{y}$ could be subdivided). I would like to briefly revert back to the discussion in Chapter 1 on the different types of "states" (see \$1.2.4) and recall that in the case of (1)-(4) these are states of affairs in which both so-called "individual level predicates", such as 'having red hair' and 'being tall', as well as "stage level predicates”, such as 'being afraid', are recognisable.

Let us now return to our analysis. If in a state of affairs conceived as a frame no individually perceptible moments can be focussed, as is precisely the case here, then of course for their part, they cannot serve as a boundary to the adjacency of the state of affairs itself.

Such combinations of aspectual basic conceptualisations within the frame can be represented by the delimitation schema as in Table (2): 
Tab. 2: Delimitation Schema 1: [(EA/nd) + (AA/nr) + (IA/ns)].

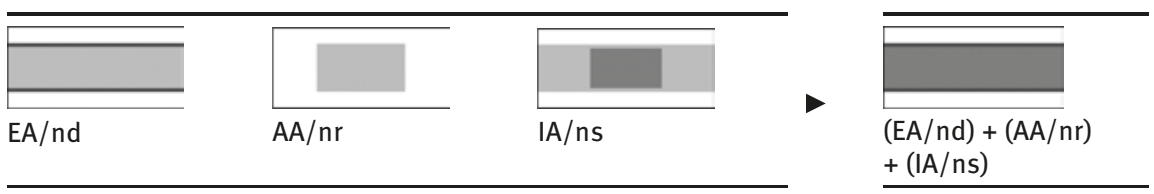

\subsubsection{Delimitation Schema 2: [(EA/nd) + (AA/nr) + (IA/s)]}

(5) It. Il gatto di Franca dormiva [Imp.] a lungo perché mangiava sempre troppo.

'Franca's cat (always) slept long because he always ate too much.'

(6) Fr. Marie mangeait [Imp.] volontiers.

'Marie enjoyed eating.'

(7) Sp. Leo dormía [Imp.] con un ojo abierto. ${ }^{3}$

'Leo slept with one eye open.'

(8) Cat. El temps passava [Imp.] i els nens creixien.

'Time passed and the children grew up.'

The states of affairs shown in examples (5)-(8) represent a combination of aspectual basic conceptualisations of the following type:

a) externally non-delimited (EA/nd)

b) not relevant to adjacency (AA/nr)

c) internally subdivided (IA/s)

In (5)-(8) a) neither a starting point $t_{x}$ nor an endpoint $t_{y}$ of the respective whole state of affairs is focussed - for neither the beginning nor the end of the long sleeping of Franca's cat (or its continuous overeating) in example (5), Marie's pleasurable eating (6), Leo's sleeping with one eye open in (7), or the passing of

3 Duerme/dormía con un ojo abierto can have two aspectual meanings: the first - represented here by dormía - is a temporally absolute meaning (he usually/always sleeps/slept with one eye open, i.e., he had this characteristic or this habit); the second, on the other hand, expresses the consideration of a particular moment $t_{x}$ of the state of affairs, in other words, what the traditional analysis of temporal-aspectual relations calls "progressive" ('Leo is/was sleeping with one eye open'). These frames have a different organisation or structure, another delimitation schema. An analysis of these cases can be found in the next chapter. 
time in example (8) are focussed: in other words, the respective states of affairs are not shown in their entirety and thus their completedness. Furthermore, it is b) logically impossible to find relevance for the adjacency of the state of affairs that Franca's cat always slept for a long time (and that Marie enjoyed eating, Leo slept with one eye open, or that time passed) because each lacks the initial boundary $t_{x}$ and the final boundary $t_{y}$ of the state of affairs itself (represented as EA/nd), which would allow the constitution of its adjacency. Finally, c) there are (substantially) different moments $t_{\mathrm{x} 1}, \mathrm{t}_{\mathrm{x} 2}, \ldots \mathrm{t}_{\mathrm{xn}}$ (which are therefore considered here in isolation, focussed on) in the fact that Franca's cat slept long (Marie liked to eat, Leo slept with one eye open and time passed).

Only if, as is the case here, there is a possibility to set further subdivision points or boundaries in the temporal structuring of the states of affairs, to recognise discrete temporal sections, does the possibility arise of a change in time. Thus, states of affairs such as those in (5)-(8), whose internal structure is temporally further subdivided, are dynamic states of affairs: Franca's cat slept through all these moments $t_{x 1}, t_{x 2}, \ldots t_{x n}$, and each of these moments can be viewed and represented individually and in isolation (similarly, Marie was eating during all the individual points of time $t_{x 1}, t_{x 2}, \ldots t_{x n}$, etc.). In other words, the states of affairs expressed in examples (5)-(8) are pluriphasic. Of course, it could be objected here that this internal subdivision is postulated without providing any linguistic evidence for it. It could also be asked how the phases of these pluriphasic states of affairs are focussed. However, a characteristic, by definition, of an onomasiological-cognitive model, such as the one presented here, is that the question of linguistic evidence cannot be posed in the same way as in a semasiological analysis. We could and should rather seek proof of the cognitive structuring of the delimitation schemas by empirical evidence, ${ }^{4}$ which, however, is beyond the limits of this investigation.

This type of combination of aspectual basic conceptualisations can be illustrated as in Table (3):

Tab. 3: Delimitation Schema 2: [(EA/nd) + (AA/nr) + (IA/s)].

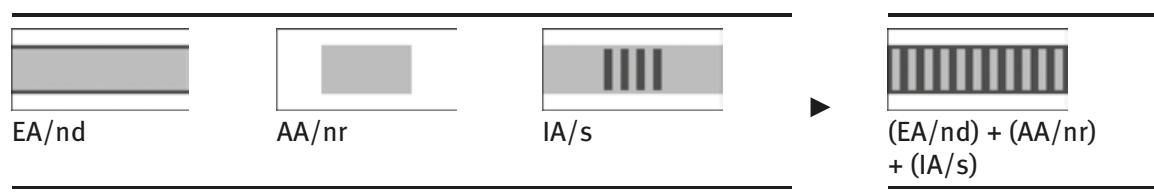

4 An approach to proving empirically the cognitive structuring of verbal semantics can be found, for example, in Siskind's work (Siskind 1997 and 2001). 


\subsubsection{Delimitation Schema 3: [(EA/d) + (AA/nr) + (IA/ns)]}

(9) It. Carlo è stato [Perf. Com.] un uomo di saldi principi. 'Charles was a man of firm principles.'

(10) Fr. Toute sa vie Marie a été [Pass. Com.] généreuse.

'All her life Marie was generous.'

(11) Sp. Nunca he tenido [Perf. Com.] miedo a volar.

'I was never afraid to fly.'

(12) Cat. La Núria va ser [Pret. Perf. Per.] una dona molt maca. 'Núria was a very beautiful woman.'

In the states of affairs presented in examples (9)-(12) a combination of aspectual basic conceptualisations of the following type can be found:

a) externally delimited (EA/d)

b) not relevant to adjacency $(\mathrm{AA} / \mathrm{nr})$

c) not internally subdivided (IA/ns)

In these examples, a) the respective states of affairs expressed - the fact that Carlo was a man of firm principles in (9), that Marie was generous all her life in (10), that I was never afraid to fly in (11), and that Núria was a very beautiful woman in (12) - are represented in their entirety. Thus, each state of affairs is represented as delimited between a starting point $t_{x}$ - the moment in which Carlo started being a man of principles, in which the life of Marie and Nurria began (and that they were then, respectively, generous and beautiful), in which I started not to be afraid of flying (which coincides with the point at which I actually started to fly and did not feel any fear at all) - and an endpoint $t_{y}$, the moment in which Carlo stopped being a man of principles (due to a moral conversion or his death), or the moment when the lives of Marie and Núria ended (and they could therefore no longer be generous or beautiful, because they no longer existed), etc. There is b) no influence of this state of affairs on its adjacency, and it is c) an internally non-subdivided, monophasic state of affairs: that Carlo was a man of principles (or that Marie was generous all her life, etc.) has no consecutive $t_{x}, t_{y}, t_{z} \ldots$ that would be individually perceptible (qualitatively different, isolable moments of firm adherence to principles or generosity, beauty or absence of fear of flying cannot be focussed in the respective frames), into which each of the states of affairs could be further subdivided, and if no individual perceptible moments can be focussed they cannot serve as the boundary of their adjacency (see b) above). 
This type of combination of aspectual basic conceptualisations can be illustrated as in Table (4):

Tab. 4: Delimitation Schema 3: [(EA/d) + (AA/nr) + (IA/ns)].

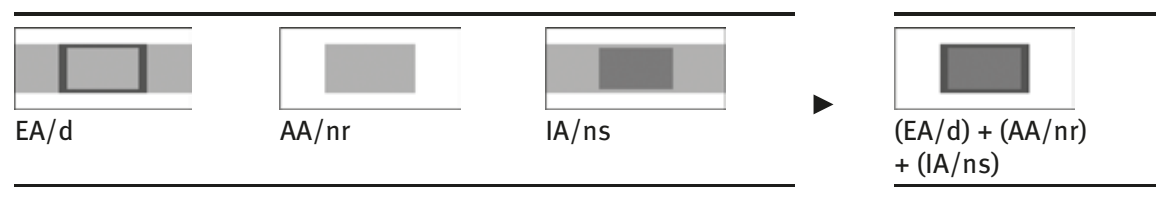

5.2.2.4 Delimitation Schema 4: [(EA/d) + (AA/nr) + (IA/s)]

(13) It. Julia ha viaggiato [Perf. Com.] molto.

'Julia has travelled a lot.'

(14) Fr. Christine cuisine [Prés.] et appelle ses filles pour manger.

'Christine cooks and calls her daughters to eat.'

(15) Sp. Marta no me habló [Perf. Sim.] durante mucho tiempo.

'Marta didn't talk to me for a long time.'

(16) Cat. Vaig veure una pel-lícula [Pret. Perf. Per.] meravellosa. [anar + Inf.] 'I saw a marvellous film.'

In examples (13)-(16), states of affairs are shown with the following combination of aspectual basic conceptualisations:

a) externally delimited (EA/d)

b) not relevant to adjacency $(\mathrm{AA} / \mathrm{nr})$

c) internally subdivided (IA/s)

In (13)-(16), a) each state of affairs - the fact that Julia has travelled a lot in (13), that Christine is preparing dinner in (14), that Marta has not spoken to me for a long time in (15) and that I (the 1st Pers. Sing. subject of the sentence) saw a marvellous film in (16) - is represented in its entirety; i.e., it is represented as delimited between a starting point $t_{\mathrm{x}}$ (the moment when Julia started to travel, Christine started to cook, Marta stopped talking to me and the film started) and an endpoint $t_{\mathrm{y}}$ (the moment Julia stopped travelling, Christine finished cooking and called her children to dinner, when Marta started talking to me again, and the moment when the film ended). However, b) this type of 
state of affairs is completely irrelevant to its adjacency: that Julia has travelled a lot or that I saw a marvellous film does not represent the end of any state of affairs in the previous adjacency (i.e., the starting of Julia's travel activity or the beginning of the film does not end anything that was taking place before the beginning of the travel activity or the film), nor the beginning of any state of affairs in the subsequent adjacency, i.e., what takes place once the travelling or film is over (nothing starts with the ending of the travelling or of the film). ${ }^{5}$ And finally, c) each state of affairs is internally subdivided, i.e., it is pluriphasic, since Julia's travelling, Christine's cooking, Marta's not talking and my watching a marvellous film have different, individually perceptible, consecutive $t_{x 1}, t_{x 2}, \ldots t_{x n}$, in all of which Julia is away, Christine is cooking, Marta is not talking to me and I was watching the film.

This type of combination of aspectual basic conceptualisations can be illustrated as in Table (5):

Tab. 5: Delimitation Schema 4: [(EA/d) + (AA/nr) + (IA/s)].

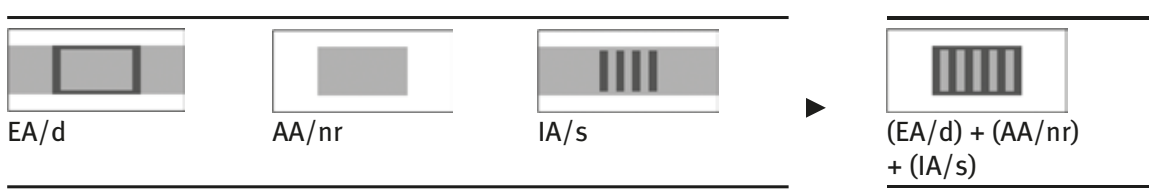

\subsubsection{Delimitation Schema 5: [(EA/d) + (AA/fr) + (IA/s)]}

(17) It. La fiamma si spense [Perf. Sem.] lentamente.

'The flame went out slowly.'

(18) Fr. Daniel a démoli [Pass. Com.] une maison (qui était délabrée).

'Daniel demolished a house.'

(19) Sp. Acabo [Pres.] de comer un osito de gominola. [acabar de + Inf.] 'I have just eaten a jelly baby.'

5 In the case of (14) the second part of the utterance (the coordinated sentence 'and calls her children to dinner') is the element that contributes to the interpretation of the first part ('Christine cooks') as 'Christine has finished cooking'. 
(20) Cat. El cotxet s'atura [Pres.] a poc a poc (i en Pau en baixa). 'The small car gradually stops.'

In examples (17)-(20), states of affairs with a combination of aspectual basic conceptualisations of the following type are represented:

a) externally delimited (EA/d)

b) with final adjacency relevance (AA/fr)

c) internally subdivided (IA/s)

The states of affairs expressed in examples (17)-(20) are a) each shown in their entirety as delimited, since the initial moment $t_{x}$ and the final moment $t_{y}$ are focussed; the respective initial and final boundaries do not coincide. In examples such as (18) and (19), this seems easier to understand: that between the initial moment $t_{x}$, in which Daniel started to demolish the house and I began to eat the jelly baby, and the final moment $t_{\mathrm{y}}$ in which Daniel completed demolishing the house and I finished eating the jelly baby, there are many more consecutive $t_{x 1}, t_{x 2}, \ldots t_{x n}$ and that $t_{x 1}$ and $t_{x 2}$ do not coincide, is provided by the world knowledge of the speaker, that for demolishing a house and eating a jelly baby time is needed. However, a state of affairs such as the one expressed in (17) may require further explanation. This is another opportunity to show the difference between the model presented here and those models based on Vendler's verb classification. Here, the comparison with Delimitation Schema 9 will be important and sheds light on various interesting issues (see §5.2.2.9, especially example (33)).

In example (17) - as in (18) and (19) - a) the state of affairs is shown in its entirety as delimited (the initial moment $t_{x}$ and the final moment $t_{y}$ of the slow extinction of the flame are focussed and its initial and final boundaries do not coincide). The semantics of its various components in mutual interaction contributes to this realisation: the morphological marking of the verb (through the Passato Remoto); semantic elements in the stem (spegnersi); adverbials such as lentamente; the presence of an individual noun functioning as a first argument (fiamma, accompanied by the determiner la). At the end of the state of affairs, the flame will not burn anymore (see b) below), and the extinction of the flame is a slow process that takes time. Thus, this is a state of affairs that shows other aspectual contents than those in (33) La fiamma si spense (in un istante). ${ }^{6}$ This is due to the presence of the temporal adverb

6 Traditionally, verbs such as spegnersi are interpreted as punctual (- durative, - telic). 
lentamente in (17), ${ }^{7}$ which - in connection with the other elements in the situation frame - contributes to this particular aspectual interpretation of the state of affairs, for while the extinction of the flame in (33) is something that is related to and represents a moment $t_{x}$ (the precise moment of extinction itself), in the case of the slow extinction in (17), this moment is interpreted and represented on the basis of the speaker's world knowledge as - so to speak - "stretched", insofar as this extended period of time contains all the moments of extinction, in which the flame became increasingly weaker or in which it seemed that the flame was just about to extinguish and yet continued to burn, albeit more weakly. The states of affairs presented in the two examples (17) and (33) are thus connected to two different frames that represent the contexts, the experiential connections, in which the speaker learned them and uses them (see also Chapter 3 in this respect). Example (17) can be interpreted in a similar way to example (20), because the stopping of the car, which is otherwise perceived in a different combination of linguistic elements as a punctual state of affairs, is also interpreted and represented by the presence of a poc a poc in such a way that in this extended period of time one can see all the $t_{x 1}, t_{x 2}, \ldots t_{x n}$ of the slowing down of the car until its final stop.

In addition, b) this type of state of affairs, as seen in (17)-(20), is relevant for its previous adjacency: it structures it by delimiting its end. That the flame has slowly gone out represents the end of the previous adjacency of the state of affairs itself, the burning of the flame (it has just gone out); that Daniel demolished a house in (18) represents the end of the existence of the house; that the subject in (19) has just finished eating the jelly baby represents the end of the jelly baby's existing; and finally, the fact that the car stopped in (20) represents the end of the previous adjacency of the state of affairs, namely the driving of the car.

In states of affairs of this type it is finally possible c) to find (i.e., to focus) the different, individually perceptible consecutive $t_{x 1}, t_{x 2}, \ldots t_{x n}$ into which they are subdivided: in (17), these are the individual, isolated and qualitatively differently perceived moments of the slow extinction of the flame (which is also connected to the presence of lentamente in the frame), which raises the question as to in what way - besides temporality, which is certainly of primary importance for delimitation - quantity plays a role in the structuring of the state of affairs; in (18) it is the individual moments of the demolishing of the

7 A modal adverb like dolcemente ('in a sweet/nice way') could have also represented the same aspectual meaning when combined with the same elements in the situation frame. In that case, dolcemente would have been reinterpreted as a temporal (i.e., aspectual) adverb and would have taken on the meaning 'slowly' in this context (see §5.2.2.6 for an analysis of such a case). 
house (in which the house is demolished); in (19) the individual moments of the eating of the jelly baby; and in (20) the stopping of the car, dependent on the presence of a poc a poc in the frame (cf. example (36), §5.2.2.9).

This type of combination of aspectual basic conceptualisations can be illustrated as in Table (6):

Tab. 6: Delimitation Schema 5: $[(E A / d)+(A A / f r)+(I A / s)]$.

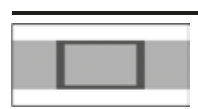

$\mathrm{EA} / \mathrm{d}$

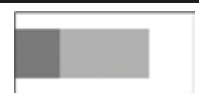

$\mathrm{AA} / \mathrm{fr}$

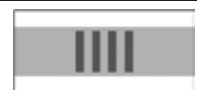

$\mathrm{IA} / \mathrm{s}$

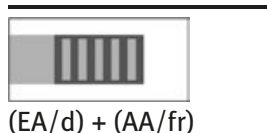

$(\mathrm{EA} / \mathrm{d})+(\mathrm{AA} / \mathrm{fr})$ $+(\mathrm{IA} / \mathrm{s})$

\subsubsection{Delimitation Schema 6: [(EA/d) + (AA/ir) + (IA/s)]}

(21) It. L'auto cominciò [Perf. Sem.] a muoversi lentamente. [cominciare $a+$ Inf.] 'The car began to move slowly.'

(22) Fr. Doucement Marie-Rose se met [Prés.] à chanter. [se mettre à + Inf.] 'Slowly, Marie-Rose starts singing.'

(23) Sp. El día nació [Perf. Sim.] tímidamente.

'The day dawned timidly.'

(24) Cat. La lluna terrestre es va formar [Pret. Perf. Per.] més tard que la resta del sistema solar. [anar + Inf.]

'The Earth's moon formed later than the rest of the solar system.'

In (21)-(24), states of affairs with the following combination of aspectual basic conceptualisations are represented:

a) externally delimited (EA/d)

b) with initial adjacency relevance (AA/ir)

c) internally subdivided (IA/s)

In these examples, a) the respective states of affairs are shown in their entirety as delimited, since both the starting point $t_{x}$ and the endpoint $t_{y}$ of the car beginning to move in (21), the beginning of Marie-Rose's singing in (22), the 
dawning of the day in (23) or the progressive formation of the moon in (24) are focussed. The initial and the final boundaries do not coincide here, because the car starts to move slowly, Marie-Rose begins to sing little by little, the day begins to break gradually and the formation of the moon takes time. The semantics of various components in mutual interaction contributes to the aspectual realisation of the respective states of affairs: the morphological marking of the verb (expressed by the Passato Remoto of the auxiliary verb in connection with the infinitive of the main verb in the periphrastic construction cominciare $a+$ infinitive in (21); the present tense of the auxiliary verb in connection with the infinitive of the main verb in the periphrastic construction se mettre $\grave{a}+$ infinitive in (22); the Perfecto Simple in (23) and the Pretèrit Perfet Perifràstic in (24)), the semantic elements in the stem (cominciare a muoversi, se mettre à chanter, nacer and formarse) ${ }^{8}$ and the adverbials (lentamente, doucement and tímidamente).

Again, comparison with examples (37)-(40) of Delimitation Schema 10 (§5.2.2.10) is very important for a better understanding of the role played by the individual components - in particular, adverbs such as lentamente -

8 Since Dowty's (1979) analysis, predicates such as formarse have been defined as "degree achievements". Dowty notes that these verbs denote a change of state and claims that they share some semantic and syntactic properties with "achievements". In investigations with standard tests, they show both telic and atelic properties. In this context see also Hay/Kennedy/ Levin (1999).

In this book, my analysis is not based on verbal properties, but rather I conceive states of affairs as situation frames. In addition, the relation between telicity and change of state (properties which are deemed essential for so-called degree achievements) is considered in a new light: the concept of telicity is radically renounced, since only purely temporal, aspectual criteria are considered here and since the idea related to telicity of a goal to be attained certainly goes beyond this simply temporal structuring of states of affairs. The notion of change of state is found again in different constellations, combinations of aspectual building blocks and realisations of the three dimensions of aspectuality (see, in particular, the realisations of AA, and in detail the analyses regarding DS 5 - DS 7, DS 9 - DS 11, DS 2/9 - DS 2/11 and DS 2/9, 9, $9, \ldots-\mathrm{DS} 2 / 11,11,11,11 \ldots$ ). Traditionally, the notions of transformative, ingressive and terminative, for example, have been used for verbs that imply a change of state. With regard to the presence of graduality (more precisely, the "degree"), this is related to the possibility of finding (i.e., focussing) - or not - different, individually perceptible consecutive $t_{x 1}, t_{x 2}, \ldots t_{x n}$ within the state of affairs which express a change of state. More specifically, DS 7, which is a combination of $(\mathrm{EA} / \mathrm{d})+(\mathrm{AA} / \mathrm{tr})+(\mathrm{IA} / \mathrm{s})$, displays a $(\mathrm{tr}=$ "transformative") change of state with internal graduality; DS 11, which is a combination of $(\mathrm{EA} / \mathrm{pd})+(\mathrm{AA} / \mathrm{tr})+(\mathrm{IA} / \mathrm{ns})$, displays a change of state without internal graduality. It is clear that no linguistic evidence obtained by tests (e.g., to investigate telicity) is possible nor useful because the addition of an element would change the whole frame. 
within and in the background of the entire frame in expressing this combination of aspectual building blocks. Direct comparison of (22) and (38), MarieRose se met à chanter, reveals that the states of affairs presented in the two examples relate to two different frames representing the contexts - the experiential connections - in which the speaker has learned them and uses them. The speaker knows, on the basis of her/his world knowledge, that while the beginning of the singing in (38) is something connected with a (particular) moment (the exact moment of the first note being sung), this moment is stretched, as in (22), when the singing begins slowly. This period of time stretched in such a way - i.e., the gradual beginning of the singing - includes all the preparations and attempts of singing: the throat-clearing as well as the hesitation before beginning.

Furthermore, states of affairs of this sort, b) are relevant to their adjacencies because they structure their respective subsequent adjacencies by representing their beginnings: the car that begins to move slowly will then continue to move; Marie-Rose who gradually starts to sing will then continue to sing; the day that breaks is there and will continue to be there; the moon that has formed will remain there for the time being.

Finally, c) in these states of affairs different, consecutive $t_{x 1}, t_{x 2}, \ldots t_{x n}$ can be perceived (those of the gradual starting to sing, etc.). This is made possible in examples (21)-(23) by the presence of elements such as lentamente, doucement and timidamente in the frame, since these elements - this was explained in a) above - stretch the interval $I=\left|\mathrm{t}_{\mathrm{y}}-\mathrm{t}_{\mathrm{x}}\right|$ which exists between the initial and final boundaries $\left(t_{x}\right.$ and $\left.t_{y}\right) .{ }^{9}$ Example (24) could be represented as internally subdivided (i.e., pluriphasic), even irrespective of the presence of such an adverb, which thus intensifies or emphasises the aspectual structuring of the situation frame because the pieces of aspectual information which convey this are connected in this frame to the verb stem: the formation of the moon is anchored in the speaker's world knowledge with a temporal graduality, which entails duration.

This type of combination of aspectual basic conceptualisations can be illustrated as in Table (7).

9 It is precisely the presence of the adverb doucement in (22), for example, that modifies the whole set of relations in the situation frame and causes this particular aspectual interpretation of the state of affairs. While the state of affairs shown below in (38) has an internal temporal structuring of the type $(\mathrm{EA} / \mathrm{pd})+(\mathrm{AA} / \mathrm{ir})+(\mathrm{IA} / \mathrm{ns})$, that in (22) has a delimitation schema of the type $(\mathrm{EA} / \mathrm{d})+(\mathrm{AA} / \mathrm{ir})+(\mathrm{IA} / \mathrm{s})$. 
Tab. 7: Delimitation Schema 6: [(EA/d) + (AA/ir) + (IA/s)].

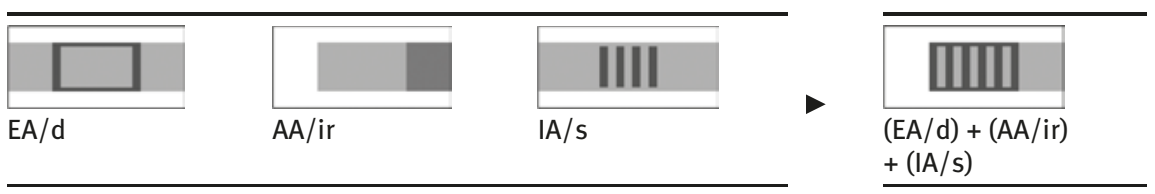

\subsubsection{Delimitation Schema 7: [(EA/d) + (AA/tr) + (IA/s)]}

(25) It. Quest'autunno le foglie sono ingiallite [Perf. Com.] molto lentamente. 'This autumn the leaves turned yellow very slowly.'

(26) Fr. Le printemps s’installa [Pass. Sim.] dans les jardins tout doucement. 'Spring came to the gardens very slowly.'

(27) Sp. El niño ha engordado [Perf. Com.] en el curso de tres años. 'The child has put on weight over the course of three years.'

(28) Cat. La nena va créixer [Pret. Perf. Per.] molt lentament. 'The girl grew very slowly.'

In (25)-(28), states of affairs with a combination of aspectual basic conceptualisations of the following type are presented:

a) externally delimited (EA/d)

b) with initial and final (transformative) adjacency relevance (AA/tr)

c) internally subdivided (IA/s)

In these examples, a) each state of affairs is shown in its entirety as delimited, for both the starting point $t_{x}$ and the endpoint $t_{y}$ of the slow yellowing of the leaves in (25), the coming of spring to the garden in (26), the increase in weight of the child (over three years) in (27) and the slow growing of the girl in (28) are focussed. Here, the initial and the final boundaries of the respective states of affairs do not coincide, because these processes are anchored in the speaker's world knowledge as those that evolve over a period of time.

In addition, b) states of affairs as in (25)-(28) are relevant to their respective adjacencies and structure their previous and subsequent adjacencies. The leaves are not yellow before turning yellow and will continue to be yellow afterwards; spring, which was not there before it came, will continue to reign in the garden thereafter; the child, who was previously thinner, will remain fatter 
after the third year if s/he does not lose weight again; finally, the girl who was smaller before growing will be taller afterwards.

Finally, c) in these states of affairs, different, successive $t_{x 1}, t_{x 2}, \ldots t_{x n}$ can be perceived separately (the different moments in which, respectively, the leaves have slowly turned yellow, spring has come to the garden, the child has become fatter, etc.). This is possible not only because of the presence of verbs such as 'to turn yellow' in (25) or 'to grow'10 in (28) (the speaker knows from her/his world knowledge that these are states of affairs with a time span), but also by the presence of adverbials such as lentamente in (25) or en el curso de tres años in (27), which further emphasise the interval $I=\left|\mathrm{t}_{\mathrm{y}}-\mathrm{t}_{\mathrm{x}}\right|$ that exists between the initial and final boundaries $\left(t_{x}\right.$ and $\left.t_{y}\right)$ of the respective states of affairs.

This type of combination of aspectual basic conceptualisations can be illustrated as in Table (8):

Tab. 8: Delimitation Schema 7: [(EA/d) + (AA/tr) + (IA/s)].

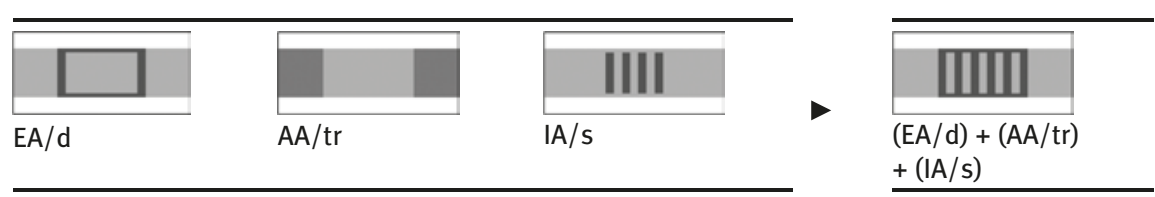

\subsubsection{Delimitation Schema 8: [(EA/pd) + (AA/nr) + (IA/ns)]}

(29) It. Bussò [Perf. Sem.] alla porta alle tre in punto.

'He knocked on the door at exactly three o'clock.'

(30) Fr. Il toussa [Pass. Sim.] fort et jeta sa cigarette par terre.

'He coughed hard and threw his cigarette on the floor.'

(31) Sp. El delincuente disparó [Perf. Sim.] un tiro con su arma.

'The criminal fired a shot with his gun.'

10 For a discussion of so-called "degree achievements", to which verbs such as ingiallire or créixer are traditionally assigned, see the analysis of DS 6 in §5.2.2.6 and, in general, Dowty (1979). 
(32) Cat. El nen va esternudar [Pret. Perf. Per.].

'The child sneezed.'

In examples (29)-(32) states of affairs with the following combination of aspectual basic conceptualisations are shown:

a) externally punctually delimited (EA/pd)

b) not relevant to adjacency $(\mathrm{AA} / \mathrm{nr})$

c) not internally subdivided (IA/ns)

In (29)-(32), a) the states of affairs are shown in their entirety as delimited, as both the starting point $t_{x}$ and the endpoint $t_{y}$ of the knocking on the door at exactly three o'clock in (29), the hard coughing in (30), the criminal's firing of the shot in (31) and the sneezing of the child in (32) are focussed. In each case, the initial and final boundaries coincide, which is evident from the presence of various elements combined in the state of affairs: in example (29) a particular aspectual content of bussare alla porta is understood (in different frames this verb can express different aspectual contents, depending on the other components in the frame; in this context, the punctual and not the reiterative meaning is expressed); furthermore, the morphological inflectional marking of the Passato Remoto and the temporal adverb alle tre in punto are both elements that contribute to a punctual interpretation. This is also the case in the other examples.

The states of affairs in (29)-(32) b) do not structure their adjacency, in fact, they are irrelevant to their respective adjacencies because the knocking on the door does not influence either the temporal constitution of its previous adjacency (that which was before the knocking) nor that of its subsequent adjacency; similarly, the coughing does not influence either the temporal constitution of what was before the coughing, or what occurred afterwards, etc.

And finally, c) no statement can be made about the further subdivisibility of the states of affairs of this type, which follows logically from the external punctual delimitation: if the knocking in (29) and the sneezing in (32) consist of $a t_{x}$ (or of the interval $\delta t_{x}$, which results from the coincidence of $t_{x}$ (the beginning of the knocking or sneezing) and $t_{\mathrm{y}}$ (the ending of the knocking or sneezing)), it is not subdivisible into further points $t_{x 1}, t_{x 2}, \ldots t_{x n}$, into which the interval $\delta t_{x}$ - as the smallest interval humanly perceivable - could be subdivided.

This type of combination of aspectual basic conceptualisations can be illustrated as in Table (9): 
Tab. 9: Delimitation Schema 8: [(EA/pd) + (AA/nr) + (IA/ns)].

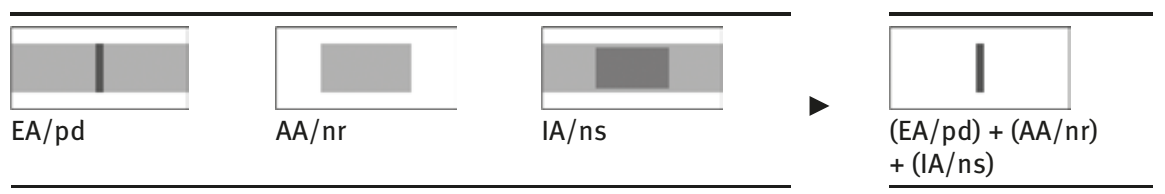

\subsubsection{Delimitation Schema 9: [(EA/pd) + (AA/fr) + (IA/ns)]}

(33) It. La fiamma si spense [Perf. Sem.] (in un istante). 'The flame went out (in an instant).'

(34) Fr. À cinq heures maman s'est endormie [Pass. Com.] dans son fauteuil. 'At five o'clock, mum fell asleep in her chair.'

(35) Sp. El autobús acaba [Pres.] de parar. [acabar de + Inf.] 'The bus has just stopped.'

(36) Cat. El cotxet es va aturar [Pret. Perf. Per.] improvisadament.

'The small car suddenly stopped.'

In (33)-(36), states of affairs with the following combination of aspectual basic conceptualisations are represented:

a) externally punctually delimited (EA/pd)

b) with final adjacency relevance (AA/fr)

c) not internally subdivided (IA/ns)

The states of affairs shown in examples (33)-(36) - the flame going out in a moment in (33), the mother falling asleep at five o'clock in (34), the bus stopping just previously in (35) and the sudden stopping of the car in (36) - a) are focussed in their entirety as delimited (and therefore as completed). In these cases, the respective initial and final boundaries $t_{x}$ and $t_{y}$ coincide, in other words, they do not represent a time span. Several of the components of the states of affairs contribute to this realisation of aspectuality: in examples (33) and (34), in particular, these are the morphological marking of the verb (by the Passato Remoto and the Passé Composé), semantic elements in the respective stems (spegnersi and s'endormir), the presence of the adverbials in un istante and à cinq heures, the presence of individual nouns acting as first arguments (fiamma and maman, the former accompanied by the determiner la). In these cases, the convergence of 
this aspectual information in the frame has a reinforcing effect (the comparison with example (17) of Delimitation Schema 5 given in §5.2.2.5 highlights the different outcomes of different interactions, because there the other adverbials had instead a corrective effect).

In addition, b) these states of affairs structure their previous adjacencies by determining their end: that the flame has gone out means that it no longer burns and, of course, that it will not go out anymore (the state of affairs is completed and irreversible); that mum fell asleep on the sofa at five o'clock means that she is no longer awake; that the bus has just stopped and the car stopped suddenly implies that they are not moving anymore.

Finally, c) logically, no statement can be made about the further subdivisibility of these punctual states of affairs: if the flame going out in a moment (just like the falling asleep of mum, or the stopping of the vehicles) consists of the $t_{x}$ of its beginning that coincides with the $t_{y}$ of its ending, this $t_{x}$ is not subdivisible into any further points $t_{x 1}, t_{x 2}, \ldots t_{x n}$. The beginning and ending of these processes is thus an interval $\delta t_{x}-$ the smallest possible interval for human perception - which, by definition, cannot be subdivided any further.

This type of combination of aspectual basic conceptualisations can be illustrated as in Table (10):

Tab. 10: Delimitation Schema 9: [(EA/pd) + (AA/fr) + (IA/ns)].

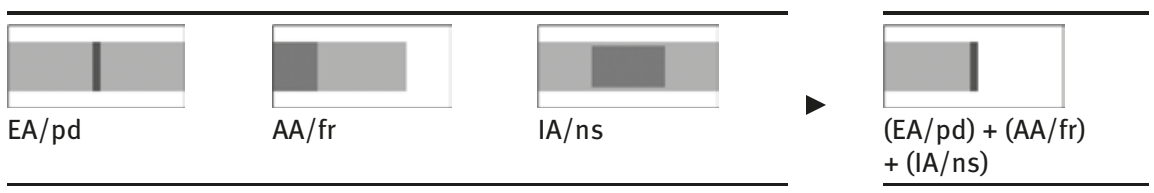

\subsubsection{Delimitation Schema 10: [(EA/pd) + (AA/ir) + (IA/ns)]}

(37) It. Entrò [Perf. Sem.] nella stanza.

'He entered the room.'

(38) Fr. Marie-Rose se met [Prés.] à chanter. [se mettre à + Inf.]

'Marie-Rose starts singing.' 
(39) Sp. Juan se ha despertado [Perf. Com.] a las tres en punto. 'Juan woke up at three o'clock.'

(40) Cat. La barca va sortir [Pret. Perf. Per.]. 'The ship departed.'

In examples (37)-(40) states of affairs with the following combination of aspectual basic conceptualisations are shown:

a) externally punctually delimited $(\mathrm{EA} / \mathrm{pd})$

b) with initial adjacency relevance (AA/ir)

c) not internally subdivided (IA/ns)

In these examples, a) the respective states of affairs are represented in their entirety as delimited, since both the starting point $t_{x}$ and the endpoint $t_{y}$ of entering the room in (37), beginning to sing in (38), waking up at exactly three o'clock in (39) and the departing of the ship in (40) are focussed. The initial and final boundaries of the states of affairs therefore coincide, because his entering the room, Marie-Rose's starting to sing, and so on, are instantaneous. If we focus on the beginning of the singing - as in a frame such as (38) where there are no further elements that influence or modify this interpretation through other (temporal) contents ${ }^{11}$ - we automatically focus on the end of this beginning, which itself has no duration.

These are also states of affairs b) that influence the beginning of their subsequent adjacencies: when he enters the room, he is in the room afterwards; when Marie-Rose begins to sing, the subsequent adjacency is then filled with singing; when Juan wakes up at three o'clock, he will be awake afterwards; and when the ship has left, it will be on its journey.

Finally, c) such states of affairs, as externally punctually delimited ones, are not internally delimitable because they display no time span: no statement can be made about the subdivisibility of the entering of the room (or the beginning to sing, etc.) because this state of affairs is also a case of an interval $\delta t_{x}$ which cannot be subdivided into any further points $t_{x 1}, t_{x 2}, \ldots t_{x n} \cdot{ }^{12}$

This type of combination of aspectual basic conceptualisations can be illustrated as in Table (11):

11 See the analysis of examples (21)-(24) of Delimitation Schema 6 (§5.2.2.6).

12 It is interesting to compare this conception of aspectuality with the traditional classification of aspect and Aktionsart. Here, it should be emphasised that si mette a cantare vs. si mise a cantare reveals a difference that manifests itself only on the temporal and not on the aspectual level. 
Tab. 11: Delimitation Schema 10: [(EA/pd) + (AA/ir) + (IA/ns)].

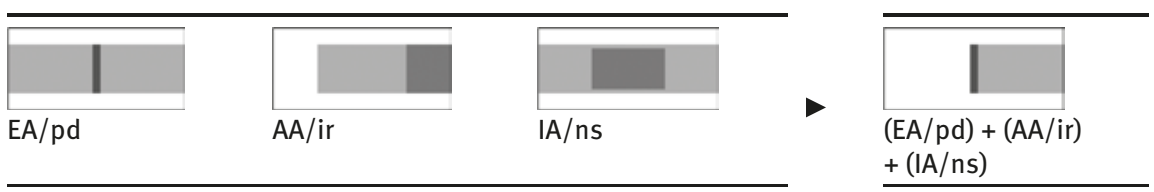

\subsubsection{Delimitation Schema 11: [(EA/pd) + (AA/tr) + (IA/ns)]}

(41) It. Il palloncino esplose [Perf. Sem.] improvvisamente (provocando il pianto dei bambini).

'The balloon suddenly burst (making the children cry).'

(42) Fr. Marie rougit [Pass. Sim.] soudainement: elle avait vu Gérard!

'Marie suddenly blushed: she had seen Gérard!'

(43) Sp. ¡He engordado [Perf. Com.] un kilo en un segundo: maldita Nocilla!

'I've put on a kilo in one second: damn Nutella!'

(44) Cat. En Xavier s'enamorà [Pret. Perf. Sim.] del mar just l'instant en què el veié.

'Xavier fell in love with the sea the moment he saw it.'

In examples (41)-(44), states of affairs with the following combination of aspectual basic conceptualisations are represented:

a) externally punctually delimited (EA/pd)

b) with initial and final (transformative) adjacency relevance (AA/tr)

c) not internally subdivided (IA/ns)

In these examples, a) the states of affairs are shown in their entirety as delimited, for both the starting point $t_{x}$ and the endpoint $t_{y}$ of the bursting of the balloon in (41), the sudden blushing of Marie in (42), the gaining of weight in a second in (43), and the instant falling in love with the sea in (44) are focussed. Here, the respective initial and final boundaries of the states of affairs coincide, because the balloon burst as instantaneously as Xavier fell in love; no period of time can be perceived in any of these states of affairs. Here too, the role played by the individual components in the frame must be taken into account: in (44), for example, these are the morphological marking of the verb (through the Preterit Perfet), the semantic elements in the stem (enamorarse) 
and the presence of the complex subframe just l'instant en què el veié, which contains further adverbial and verbal punctual determinations.

Furthermore, b) these states of affairs are relevant to their adjacencies, structuring both their previous and their subsequent adjacencies: the balloon is intact before bursting and will be damaged after the bursting; Marie is not red before blushing and will continue to be so afterwards; I am one kilo lighter before gaining weight and will (unfortunately) remain a kilo heavier afterwards, and Xavier is not in love before falling in love and will continue to be in love afterwards.

Finally, c) no statement can be made about the subdivisibility of states of affairs of this kind. The falling in love with the sea in (44) is - like all punctual states of affairs - not subdivisible into any further points $t_{x 1}, t_{x 2}, \ldots t_{x n}$ : the beginning of Xavier's falling in love coincides with its end and therefore displays no time span in which further points $t_{x 1}, t_{x 2}, \ldots t_{x n}$ of falling in love could be perceived in isolation.

This type of combination of aspectual basic conceptualisations can be illustrated as in Table (12):

Tab. 12: Delimitation Schema 11: [(EA/pd) + (AA/tr) + (IA/ns)].

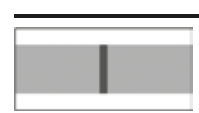

$\mathrm{EA} / \mathrm{pd}$

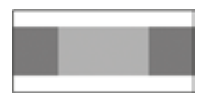

$\mathrm{AA} / \mathrm{tr}$

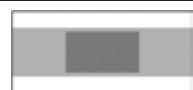

$\mathrm{IA} / \mathrm{ns}$

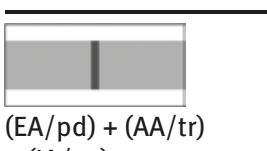

$+(\mathrm{IA} / \mathrm{ns})$

\subsubsection{Delimitation Schema 12: [(NEA) + (NAA) + (NIA)]}

(45) It. I neonati mangiano [Pres.] e dormono [Pres.].

'Babies eat and sleep.'

(46) Fr. Les hommes sont [Prés.] mortels.

'Men are mortal.'

(47) Sp. ¡La vida es [Pres.] breve!

'Life is short!' 
(48) Cat. Els nens creixen [Pres.]. ${ }^{13}$

'Children grow up.'

Finally, in examples (45)-(48) states of affairs of a very special kind are represented, namely those in which no combination of the aspectual basic conceptualisations of the three dimensions of aspectuality is evident. Instead, we have here a general impossibility of delimitation. In other words, they are atemporal states of affairs, where no particular realisation of aspectuality can be represented. They are:

a) not externally delimitable (NEA)

b) relevance for adjacency cannot be determined (NAA)

c) not internally subdivisible (NIA)

They thus represent combinations of all three perspectives of aspectuality on an abstract, logical level of the impossibility of their determination, in other words non-aspectuality.

As long as the states of affairs presented in examples (45)-(48) are intended and understood as universal statements about the world in general, a) they are not delimitable. Indeed, in this framework of interpretation they are absolutely valid and therefore alien to any temporal delimitation: in the 'shortness of life' in (47) there are neither aspectual markings on the predicate (which is expressed in the present tense), nor contents in the first argument (la vida, which is 'life in general', the life of all people in the world and in the course of time) that would allow for an aspectual delimitation (and of course the same applies to the babies' eating and sleeping in (45), to the 'mortality' of men in (46), and to the growing of children in (48)).

Furthermore, b) non-delimitable states of affairs are those in which no statement regarding their adjacency relevance can be made (because they also have no delimitation that could make up an adjacency).

13 If example (48) were contextualised in a non-universally valid interpretation frame, in some other situation frame, then els nens would not be all children but rather particular children, such as mine, whose growing I am reporting on, and it would no longer be a generally valid state of affairs but one that would have to be interpreted as progressive (in English 'The children are growing up'). Similar examples of aspectual polysemy have already been pointed out. In this case, a different delimitation schema would be assigned to the states of affairs, which would have a further level of focussing: DS 2/11, 11, 11, . : $[((\mathrm{EA} / \mathrm{nd})+(\mathrm{AA} / \mathrm{nr})+(\mathrm{IA} / \mathrm{s}))>((\mathrm{EA} / \mathrm{pd})+$ $(\mathrm{AA} / \mathrm{tr})+(\mathrm{IA} / \mathrm{ns})),((\mathrm{EA} / \mathrm{pd})+(\mathrm{AA} / \mathrm{tr})+(\mathrm{IA} / \mathrm{ns})),((\mathrm{EA} / \mathrm{pd})+(\mathrm{AA} / \mathrm{tr})+(\mathrm{IA} / \mathrm{ns})), \ldots$. $)$. See Chapter 6 (in particular §6.2.2.8) for an exact analysis of such cases. 
Finally, c) no statement can be made as to their subdivisibility, since states of affairs without any temporal delimitation cannot be further subdivided into subintervals: the shortness of life is an eternal state of affairs, valid beyond time, and thus would not be subdivisible into any points $t_{x 1}, t_{x 2}, \ldots t_{x n}$ of life being short, and if no single perceptible moments can be focussed in the eternal shortness of life, these cannot serve as the boundary of an adjacency (cf. b) above).

This type of combination of aspectual basic conceptualisations can be illustrated as in Table (13):

Tab. 13: Delimitation Schema 12: [(NEA) + (NAA) + (NIA)].

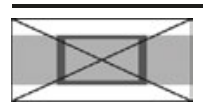

NEA

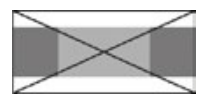

NAA

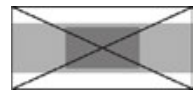

NIA

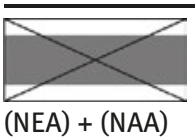

$+(\mathrm{NIA})$

\subsection{A third interim conclusion}

In this chapter, a new onomasiological and unidimensional model for describing the interaction of aspectual content in states of affairs - understood as frame structures - was presented, which makes use of a classification principle based on a basic human cognitive ability: the delimitation principle. Aspectuality is understood here as aspectual delimitation and defined as a universal content category that expresses the possibilities of external (absolute delimitation or non-delimitation), adjacency-related (adjacency relevance or non-relevance) and internal (subdivision or non-subdivision) temporal structuring of a state of affairs.

Since the traditional terminology for aspectual categories arises from a semasiological perspective and is based on the distinction between two categories within the more general semantic field of aspectuality, it could not be used in the present study. A general revision of the terminology was therefore necessary, which, of course, also reflects a theoretical difference at the foundational level of the category: there is no inevitable correspondence between the realisations of aspectuality presented here and the semasiologicallyobtained language-particular categories of aspect and Aktionsart.

At this point, I should make explicit what has already been hinted at or indicated in some of the footnotes, namely that it is no coincidence that no 
(syntactic) tests were used in the classification presented here for analysing the frames under consideration. In aspectology, it is common in making verb classifications to verify them by adding adverbial elements, such as "in $\mathrm{x}$ hours" or "for y days", to test the properties of predicates (according to known criteria of telicity, durativity, etc.). This is neither useful nor possible when investigating states of affairs considered as frames, as each addition of an adverbial test element modifies the entire frame and therefore its aspectual interpretation.

The inventory given in this chapter of the various realisations of aspectual content (aspectual basic conceptualisations) and their possible (and impossible) combinations within a frame also represents an application of the model developed here. I have shown that by analysing aspectuality as a universal semantic category it is possible to describe the aspectual content of states of affairs in a way that is at least as fine-grained as those methods that make use of the means advocated by bidimensional approaches - including the subdivision of aspectual content into two categories, aspect and Aktionsart, and the description of the convergence of different subtypes of these two categories. The second level of perspectivisation in situation frames presented in the next chapter will lend support to this and develop it further. Romance verbal periphrases, which are particularly common on the second level, will serve as the basis for further examination of the model regarding its possibilities for description and analysis.

We have already seen on these pages two advantages of the model: it is cognitively adequate, since it departs from a single and fundamental cognitive principle, the delimitation principle, and it is semantically homogeneous, since it can describe all possible contexts with combinations of the three perspectives of aspectuality which provide a limited but comprehensive set of basic conceptualisations. 
